Published in final edited form as:

Angew Chem Int Ed Engl. 2005 November 4; 44(43): 7082-7085.

\title{
Diels-Alder Reactions:
}

\section{Catalytic Asymmetric Nitroso-Diels-Alder Reaction with Acyclic Dienes**}

\author{
Yuhei Yamamoto and Hisashi Yamamoto[ $\left.{ }^{*}\right]$ \\ ["]Department of Chemistry, The University of Chicago, 5735 South Ellis Avenue, Chicago, IL 60637 \\ (USA), Fax: (+ 1)773-702-0805, E-mail: yamamoto@uchicago.edu
}

\section{Keywords}

amino alcohols; asymmetric catalysis; cycloaddition; dienes; nitroso compounds

\begin{abstract}
The nitroso-Diels-Alder reaction has long been a valuable synthetic operation for multistep syntheses given that the resulting adducts serve as 1-amino-4-hydroxy-2-ene derivatives after a single step. Subsequent to earlier studies by Kresze and co-workers[1] on the use of simple nitroso derivatives, many research groups have made significant contributions to the steady improvement of this methodology.[2] Recently, we enhanced this transformation to catalytic and enantioselective methods through the use of nitrosopyridine as a dienophile in the presence of a chiral copper catalyst.[3] Unfortunately, the new asymmetric reaction did not proceed as smoothly for acyclic dienes as it did for cyclic systems, which therefore limits its range of application. Herein, we report catalytic regio-, diastereo-, and enantioselective nitroso-Diels -Alder reactions of acyclic 2-silyloxy-1,3- dienes that have a broad substrate scope. The pathway for the present catalytic enantioselective transformation is outlined in Scheme 1.
\end{abstract}

The nitroso-Diels-Alder reaction of pentadiene and 6- methyl-2-nitrosopyridine in the presence of $\left[\mathrm{Cu}(\mathrm{MeCN})_{4}\right.$-(segphos) $] \mathrm{PF}_{6}$ gave a mixture of 1- and 4-amino derivatives in a 3:1 ratio with up to $10 \% e e$. The reactivity of the diene was increased, and $(2 Z, 4 E)-3-$

trimethylsilyloxy-2,4-hexadiene[4] (1a) was examined in the presence of a catalytic amount of $\left[\mathrm{Cu}(\mathrm{MeCN})_{4}(\right.$ segphos $\left.)\right] \mathrm{PF}_{6}$. Although this experiment gave complete regioselectivity[5] (4silyloxy/5-silyloxy $\geq 99: 1$ ), the enantioselectivity (16\% ee for the 4-silyloxy derivative) remained low. Surprisingly, the low enantioselectivity was improved significantly by simply

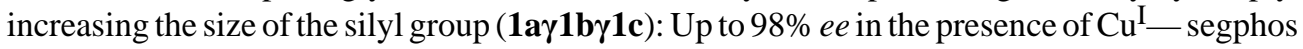
[6] and $>99 \%$ ee with $\left[\mathrm{Cu}(\mathrm{MeCN})_{4}\right.$-(difluorophos) $] \mathrm{PF}_{6}[7]$ were attained in the reaction of the triisopropylsilyl derivative 1c (Table 1).

The applicability of this reaction was demonstrated for the functionalized dienes $\mathbf{1 c - m}$ (summarized in Table 2). All of the reactions proceeded in high yields and enantioselectivities, with complete regio- and diastereoselectivities. The dialkyl-substituted dienes generally gave high enantioselectivities (Table 2, entries 1-3 and 11). Interestingly, reactions with trienes proceeded in a completely regioselective manner and provided only a single regioisomer (Table 2, entries 4 and 5).[8] Phenyl-substituted alkenes $\left(R^{2}=P h\right)$ gave a relatively lower enantioselectivity (Table 2, entries 6 and 10), whereas methoxyphenyl derivitive $\mathbf{1 i}$ and heteroaromatic 1j gave high enantioselectivities (Table 2, entries 7, 8). Lewis basic substituents

\footnotetext{
${ }^{[* *}$ Support for this research was provided by the National Institutes of Health (NIH) (GM068433-01) and a grant from the University of Chicago. We acknowledge Dr. Ian Steele for X-ray crystallographic measurements and Dr. Antoni Jurkiewicz for technical support with NMR spectroscopy. We thank Takasago International Corporation for its generous gift of $(S)$-segphos, and the Merck Research Laboratoriesfor their generous support. Y.Y. thanks Dr. K. Suzuki, BANYU Pharmaceutical Co. Ltd., for generous support.

Supporting information for this article is available on the WWW under http://www.angewandte.org or from the author.
} 
such as protected alcohols (Table 2, entry 3) and ester functional groups (Table 2, entries 10 and 11) were also used in the reaction and gave highly functionalized products enantioselectively.

The products $\mathbf{3 c}-\mathbf{m}$ can be cleanly converted into the respective protected amino alcohol. For example, after hydrolysis of the silyl enol ether $3 \mathbf{c}$ by $\mathrm{TBAF} / \mathrm{AcOH}$, reduction of the ketone gave the corresponding alcohol $\mathbf{6}$ as a single diastereomer.[8] Further transformations then gave the protected amino alcohol with a defined configuration that is found in several important natural products (Scheme 2).[9]

The absolute and relative configurations of the nitroso- Diels-Alder adducts were assigned by X-ray crystallographic analysis. Compound $\mathbf{8}$ was prepared under the standard reaction conditions discussed above, then further transformed into the 3,5-dinitrobenzoic acid ester $\mathbf{9}$, which was crystallized from $\mathrm{Et}_{2} \mathrm{O}$ (Scheme 3, Figure 1).[8]

The absolute stereochemical course of the reaction was found to be in accordance with the mechanistic model we previously reported (Scheme 4).[3] This model strongly supports the importance of the pyridine moiety in the formation of a highly organized chelating intermediate during the reaction. Such an effect could not be expected for nitrosobenzene.[2i]

The acyclic nitroso-Diels-Alder reaction proceeds exceedingly smoothly with TIPS derivatives, but rather slowly with TMS ethers, a fact that is of great mechanistic interest. 6Methyl-2-nitrosopyridine (1 equiv) was treated with a 1:1 mixture of two silyloxydienes (1.4 equiv each) in competitive experiments with and without the use of a copper catalyst [Eq. (1)]. The OTIPS diene was clearly shown to be far more reactive than the OTMS or OTBS dienes. $[10,11]$ A similar trend of differences in reactivity was observed for the Diels-Alder reaction of maleic anhydride with and without Lewis acid catalysis [Eq. (2)].

The above reactions provide strong evidence that the high reactivity arises from the bulk of the TIPS group, which forces the diene to adopt an s-cis configuration in favor of the concerted [4+2] cycloaddition reaction [Eq. (3)].[12] A large NOE interaction (10.7\%) was observed between $\mathrm{H} 1$ and $\mathrm{H} 4$ of the OTIPS diene, whereas no significant NOE interaction was observed for the OTMS diene.[13] The difference in reactivity between $\mathrm{Me}_{3} \mathrm{Si}$ and $i \mathrm{Pr}_{3} \mathrm{Si}$ can also be attributed to the exceedingly rapid coppercatalyzed nitroso-Diels-Alder reaction.

In summary, we have developed a highly practical and promising method for the regio-, diastereo-, and enantioselective introduction of oxygen and nitrogen groups into simple acyclic unsaturated ketones.

\section{References}

[1]. a) Kresze G, Firl J. Tetrahedron 1968;24:1043-1050. b) Nitsch H, Kresze G. Angew. Chem 1976;88:801.Angew. Chem. Int. Ed. Engl 1976;15:760.

[2]. For reviews, see:Streith, J.; Defoin, A. Synthesis. 1994. p. 1107-1117. b) Vogt PF, Miller MJ. Tetrahedron 1998;54:1317-1348.for recent reports, see: c) Meekel AAP, Resmini M, Pandit UK. Bioorg. Med. Chem 1996;4:1051-1057. [PubMed: 8831976] d) Zhang D, Süling C, Miller MJ. J. Org. Chem 1998;63:885-888. [PubMed: 11672089] e) Aoyagi S, Tanaka R, Naruse M, Kibayashi C. J. Org. Chem 1998;63:8397-8406. f) Gouverneur SJ, McCarthy J, Mineur C, Belloti D, Dive G, Ghosez L. Tetrahedron 1998;54:10537-10554. g) Arribas C, CarreñHo MC, García-Ruano JL, Rodríguez JF, Santos M, Sanz-Tejedor MA. Org. Lett 2000;2:3165-3168. [PubMed: 11009372] h) Wang Y-C, Lu T-M, Elango S, Lin C-K, Tsai C-T, Yan Y-H. Tetrahedron: Asymmetry 2002;13:691-695. i) Lightfoot AP, Pritchard RG, Wan H, Warren JE, Whiting A. Chem. Commun 2002:2072-2073. j) Flower KR, Lightfoot AP, Wan H, Whiting A. J. Chem. Soc. Perkin Trans. 1 2002:2058-2064. k) Ding X, Ukaji Y, Fujinami S, Inomata K. Chem. Lett 2003;32:582-583. 1) Miller C, Batey RA. Org. Lett 2003;5:699-702. m) Yamamoto Y, Momiyama N, Yamamoto H. J. 
Am. Chem. Soc 2004;126:5962-5963. [PubMed: 15137750] n) Geraldine C, Marion D, Nicolas B, Cyrille K. Org. Lett 2004;6:2449-2451. [PubMed: 15228301] o) Chow CP, Shea KJ. J. Am. Chem. Soc 2005;127:3678-3679. [PubMed: 15771485]

[3]. Yamamoto Y, Yamamoto H. J. Am. Chem. Soc 2004;126:4128-4129. [PubMed: 15053601]

[4]. Dossetter AG, Jamison TF, Jacobsen EN. Angew. Chem 1999;111:2549-2552.Angew. Chem. Int. Ed 1999;38:2398-2400.

[5]. a) Boger DL, Patel M, Takusagawa F. J. Org. Chem 1985;50:1911-1916. b) McClure KF, Danishefsky SJ. J. Org. Chem 1991;56:850-853. c) Gouverneur V, Ghosez L. Tetrahedron: Asymmetry 1991;2:1173-1176. d) Cabanal-Duvillard I, Berrien J-F, Ghosez L, Husson H-P, Royer J. Tetrahedron 2000;56:3763-3769. e) Leach AG, Houk KN. J. Org. Chem 2001;66:5192-5200. [PubMed: 11463273]

[6]. Saito T, Yokozawa T, Ishizaki T, Moroi T, Sayo N, Miura T, Kumobayashi H. Adv. Synth. Catal 2001;343:264-267.

[7]. a) Jeulin S, de Paule S. Duprat, Ratovelomanana-Vidal V, Gênet J-P, Champion N, Dellis P. Angew. Chem 2004;116:324-329.Angew. Chem. Int. Ed 2004;43:320-325. b) Leroux F, Gorecka J, Schlosser M. Synthesis 2004:326-328. c) Jeulin S, de Paule S. Duprat, Ratovelomanana-Vidal V, Gênet J-P, Champion N, Dellis NP. Proc. Natl. Acad. Sci 2004;101:5799-5804. [PubMed: 15031423]

[8]. www.ccdc.cam.ac.uk/data_request/cifCCDC-271386 (3g), -271387 (6), and -271388 (9) contain the supplementary crystallographic data for this paper. These data can be obtained free of charge from the Cambridge Crystallographic Data Centre via

[9]. For example, fumonisin $B_{2}$ : a) Lee YS, Peng LF, Kishi Y. J. Org. Chem 1997;62:5666-5667. b) Sakai N, Ohfune Y. J. Am. Chem. Soc 1992;114:998-1010.

[10]. RückerCChem. Rev1995951009For a review on use of the TIPS group in organic chemistry, see:

[11]. MayrHKempfBOfialARAcc. Chem. Res2003366677For a review on $\pi$ nucleophilicity, see: [PubMed: 12534306]

[12]. A similar observation of the relationship between the enantioselectivity and size of the silicon group was observed: a) Corey EJ, Guzman-Perez A, Loh T-P. J. Am. Chem. Soc 1994;116:3611-3612. b) Danishefsky S, Chao K-U, Schulte G. J. Org. Chem 1985;50:4650-4652.

[13]. The NOESY experiment was conducted with both dienes (see Supporting Information) 
Scheme 1.

The present pathway for the catalytic enantioselective transformation of acyclic 2-silyloxy-1,3dienes. TIPS=triisopropylsilyl, $\mathrm{Py}=$ pyridine. 
Table 1.

Effect of size the of the silicon group on the enantioselectivity.[a] The reaction was conducted with catalyst (10 mol\%), nitrosopyridine (1 equiv), and silyloxydiene (1.4 equiv) in a $\mathrm{N}_{2}$ atmosphere at $-85^{\circ} \mathrm{C}$ and gradually warmed to $-20^{\circ} \mathrm{C}$ over $5 \mathrm{~h}$. [b] The ee valueswere determined by HPLC (Supporting Information). TMS=trimethylsilyl. 


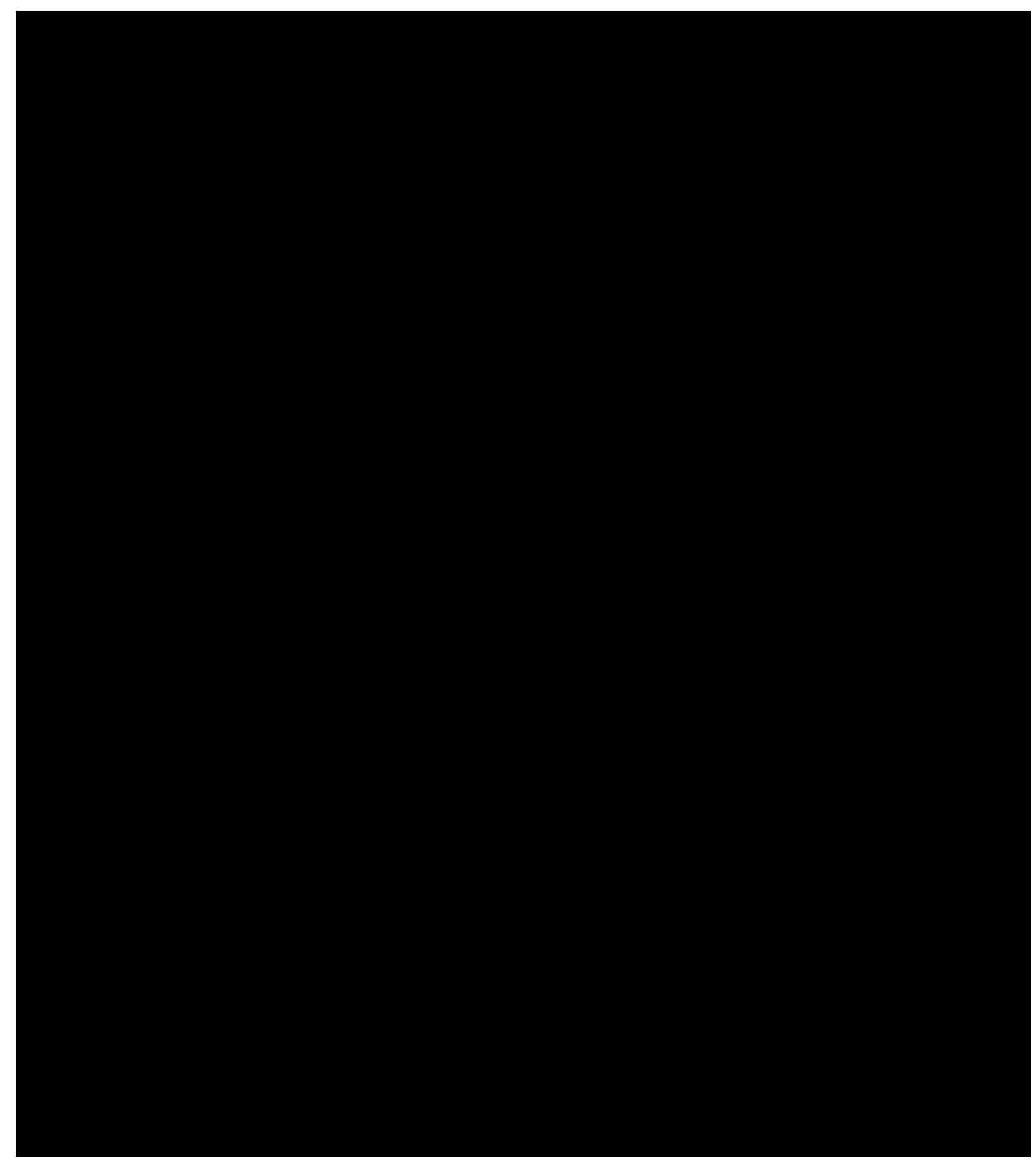

Table 2:

Reaction with various dienes. [a] The reaction was conducted with catalyst (10 mol\%), nitrosopyridine ( 1 equiv), and silyloxydiene ( 1.2 equiv) under $\mathrm{N}_{2}$ at $-85^{\circ} \mathrm{C}$ and gradually warmed to $-20^{\circ} \mathrm{C}$ over $5 \mathrm{~h}$. [b] The $e e$ values were determined by HPLC analysis (Supporting Information). 


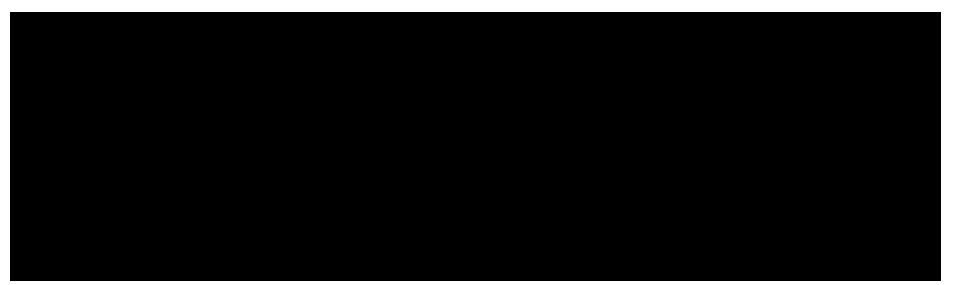

Scheme 2.

Conversion of the nitroso-Diels-Alder adduct into the protected amino alcohol 7. Reaction conditions: a) $\mathrm{Pd} / \mathrm{C} 10 \%, \mathrm{H}_{2}, \mathrm{MeOH}$; then 2,2-dimethoxypropane, TsOH; b) $\mathrm{Ts}_{2} \mathrm{O}$, diethylisopropylamine, 1,2-dichloroethane;c) TsOH, MeOH; then TBSOTf, 2,6-lutidune, $\mathrm{CH}_{2} \mathrm{Cl}_{2}$; d) MeOTf, $\mathrm{CH}_{2} \mathrm{Cl}_{2}$; then $10_{\mathrm{N}} \mathrm{KOH}, \mathrm{MeOH}$. TBAF=tetrabutylammonium fluoride, $\mathrm{Ts}=p$-toluenesulfonyl, TBS=tert-butyldimethylsilyl, $\mathrm{Tf}=$ trifluoromethanesulfonyl. 


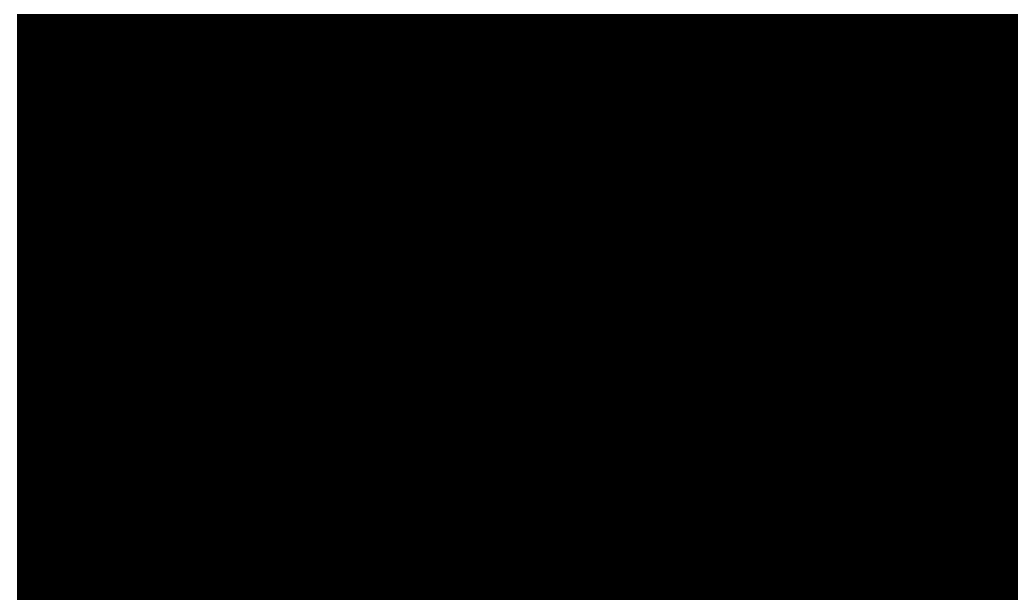

Scheme 3.

Transformation of the alcohol 8 into the 3,5-dinitrobenzoic acid ester 9. TEA=triethylamine, DMAP=4-(dimethylamino)pyridine. 


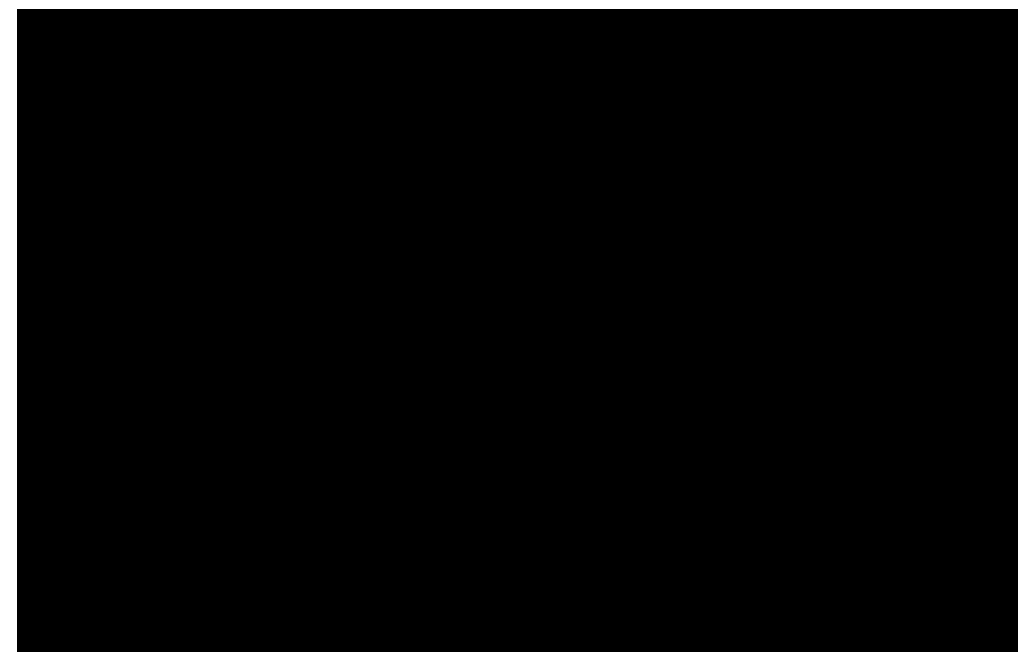

Figure 1.

$\mathrm{X}$-ray crystallographic structure of $9, \mathrm{Et}_{2} \mathrm{O}$ is omitted for clarity. Elipsoids drawn at the $50 \%$ probability level 


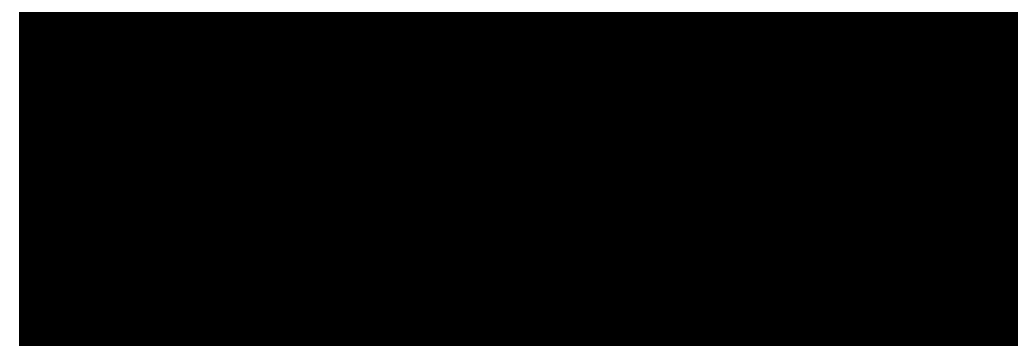

Scheme 4.

Model for a plausible chelate intermediate. 


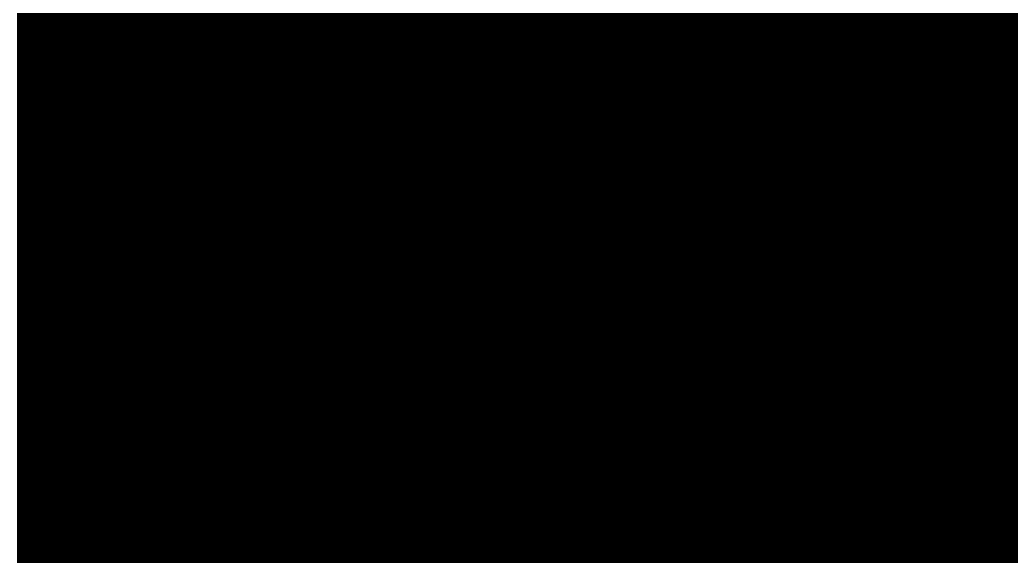

Equation 1. 


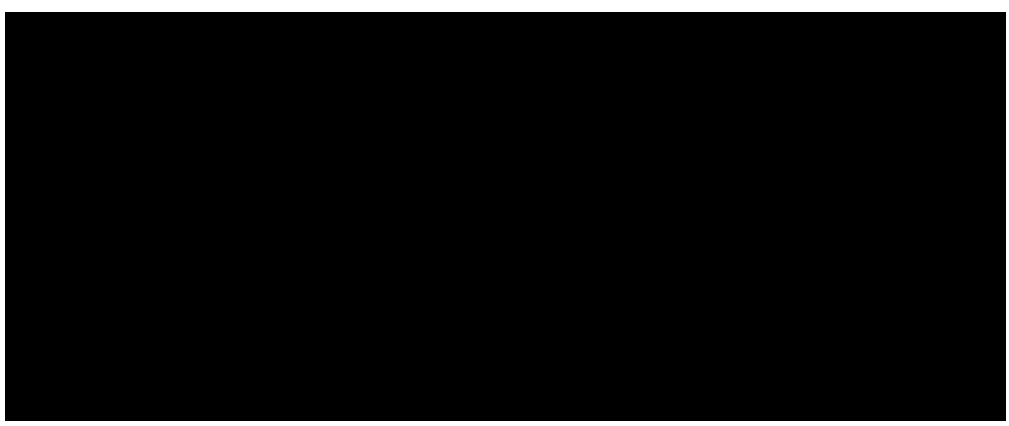

Equation 2. 
Equation 3.

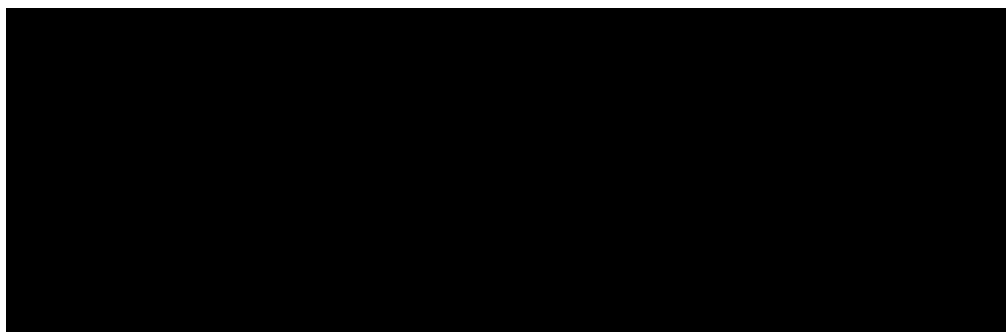

\section{Equation 3.}

